This article was downloaded by: [Australian National University Library]

On: 18 February 2009

Access details: Access Details: [subscription number 907447456]

Publisher Routledge

Informa Ltd Registered in England and Wales Registered Number: 1072954 Registered office: Mortimer House, 37-41 Mortimer Street, London W1T 3JH, UK

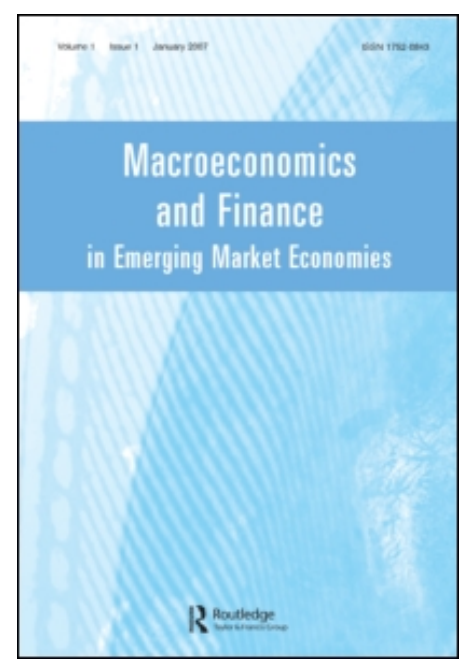

Macroeconomics and Finance in Emerging Market Economies

Publication details, including instructions for authors and subscription information:

http://www.informaworld.com/smpp/title content=t762290974

\title{
A Divisia type saving aggregate for India
}

\section{Raghbendra Jha a; Ibotombi S. Longjam ${ }^{b}$}

a ASARC, Division of Economics, Research School of Pacific \& Asian Studies, Australian National University, Canberra, Australia ${ }^{b}$ American Express, Gurgaon, India

Online Publication Date: 01 March 2008

To cite this Article Jha, Raghbendra and Longjam, Ibotombi S.(2008)'A Divisia type saving aggregate for India',Macroeconomics and Finance in Emerging Market Economies, 1:1,51 - 66

To link to this Article: DOI: $10.1080 / 17520840701834966$

URL: http://dx.doi.org/10.1080/17520840701834966

\section{PLEASE SCROLL DOWN FOR ARTICLE}

\footnotetext{
Full terms and conditions of use: http://www.informaworld.com/terms-and-conditions-of-access.pdf

This article may be used for research, teaching and private study purposes. Any substantial or systematic reproduction, re-distribution, re-selling, loan or sub-licensing, systematic supply or distribution in any form to anyone is expressly forbidden.

The publisher does not give any warranty express or implied or make any representation that the contents will be complete or accurate or up to date. The accuracy of any instructions, formulae and drug doses should be independently verified with primary sources. The publisher shall not be liable for any loss, actions, claims, proceedings, demand or costs or damages whatsoever or howsoever caused arising directly or indirectly in connection with or arising out of the use of this material.
} 


\title{
RESEARCH ARTICLE
}

\section{A Divisia type saving aggregate for India}

\author{
Raghbendra Jha ${ }^{\mathrm{a} *}$ and Ibotombi S. Longjam ${ }^{\mathrm{b}}$ \\ ${ }^{a}$ ASARC, Division of Economics, Research School of Pacific \& Asian Studies, Australian National \\ University, Canberra, Australia; ${ }^{b}$ American Express, Gurgaon, India
}

(Final version received June 2007)

\begin{abstract}
Indian financial sector reforms initiated in 1991-92 have significantly affected user costs of assets and have resulted in significant substitution among them. Thus there is a need to develop a measure of savings that reflects household choice over assets more accurately than the simple sum. An advantage of monetary aggregates that are based on microtheoretic foundations, for example, the Divisia index, is that no a priori assumptions about asset substitutability need be imposed. We construct Divisia subaggregates of the financial assets component of Indian household savings and an overall aggregate of financial savings and demonstrate their superiority to the simple sum constructs.
\end{abstract}

Keywords: Divisia aggregates, financial savings

\section{Introduction}

Gross financial assets in the household sector's savings in India, as in most countries, are measured as a sum of the component assets. In the Indian case these assets include, broadly, currency, deposits, net claims on government, shares and debentures, insurance and provident funds. However, aggregating these by simple summation implicitly assumes that the individual assets are perfect substitutes. The fact that most economic decisionmakers hold a portfolio of assets that have significantly different opportunity costs, rather than a single asset with the lowest cost, implies that the owners do not regard these assets as perfect substitutes. Further, with the acceleration of financial liberalization, demand for financial assets in India has become more responsive to the movements of interest rates. More formally Jha and Longjam (2006) demonstrate that household preference structure has a sub-preference in that contractual savings (insurance and provident funds) can be separated out from other assets. It would thus appear likely that quantity indices for financial services based on appropriate microfoundations like Divisia quantity index will dominate the simple sum index. As Drake, Mullineux and Agung (1997) point out, progress towards financial integration is not only likely to increase the usefulness of Divisia quantity indices relative to simple sum, but also lead to homogenization of behaviour. The present paper purports to construct such an index.

In India, the pace of financial innovation was relatively slow until the initiation of the financial liberalization programme begun in 1991-92 and sustained thereafter. As a consequence the user costs of assets have varied considerably and resulted in significant substitution among these assets. Hence there is a need to develop an aggregate measure of savings that would more accurately reflect household choice over various assets than the

*Corresponding author. Email: r.jha@anu.edu.au 
simple sum. As user costs of assets change so does the composition of the financial savings aggregate. The standard method of simple summation cannot capture this. Chetty (1969), Friedman and Schwartz (1970), Barnett (1980, 1982) and Hirayama and Kasuya (1996) attempted to investigate the microfoundations of the statistical index number theory for aggregating monetary assets. An advantage of monetary aggregates that are derived from such microeconomic models is that no a priori assumptions about the substitutability of assets need to be imposed. A Divisia aggregate has some theoretical advantages in this regard but since the estimation of this aggregate is computationally difficult, the extent of its superiority over the simple sum becomes an important empirical consideration. In this paper we construct Divisia subaggregates of the financial assets of the household savings based on results from weak separability parametric and non-parametric tests. From these subaggregates we construct an overall aggregate of financial savings in India. We then compare the constructed index and the simple sum. By construction, the Divisia index is more theoretically sound. We also compare the two over simple macro models and systems of demand equations and find that the Divisia again outperforms the simple sum. Finally we compare the two according to their information content and find the two to have similar information content. Hence, on balance, the Divisia construct is superior to the simple sum.

This paper is organized as follows. Section 2 briefly discusses developments in the Indian financial sector, particularly interest rate structures. The construction of the Divisia indices for the savings aggregates is explained in Section 3. Section 4 compares the Divisia and the simple sum indices over a System of Demand Equations. An empirical exercise on the presence of economic information content of the Divisia index using the standard norms of information theory is given in Section 5. Section 6 concludes.

\section{Innovation in the Indian financial sector}

Indian financial sector reforms began in the 1970s. Nevertheless, until the liberalization programme begun in 1991, the financial system was closely linked to public finance (Gupta 1970). There were complex regulations on the deposit and lending rates and major chunks of credit to the government and priority sector were channelled at rates much lower than market rates through high cash reserve requirements (CRR) and statutory liquidity requirements (SLR). ${ }^{1}$ There was very little competition in the financial markets as most financial institutions were in the public sector. But after 1990, the financial sector went through sustained transformation as various measures were undertaken to increase resource mobilization and improve allocation in the real economy. The first Narasimham Committee Report (released in November 1991) provided a blueprint for financial reform, which included reductions in SLR and CRR, phase-out of directed credits and deregulation of the interest rates in a phased manner.

The most significant reform was that of the interest rate structure. After 1991, administered interest rates on various instruments (deposits and loans) were slowly phased out. Interest rates on time deposits were decontrolled in a sequential manner beginning with longer-term deposits and then deposits of shorter maturity periods. With effect from October 1997, all interest rates including on 15-day deposits have been freed. The only exception is the rate on saving bank deposits, which the Reserve Bank of India (RBI) controls currently at $4 \%$ per annum. Lending rates were also freed in a similar fashion. ${ }^{2}$

Advocates of financial reforms support interest rate liberalization, as banks are allowed greater flexibility and are induced for competition, thus making the financial system more effective. The decontrolling of the interest rates on deposits and lending has led to significant improvement in the management and the performance of banks and 
other financial institutions (Ahluwalia 1999). Banks are able to vary rates charged to borrowers according to their cost of funds and also to reflect the creditworthiness of different borrowers. Similarly, they can offer varying deposit rates to reflect competitive conditions and to maintain real returns.

Administered interest rates on public and provident funds as well as those on small savings have also been lowered. Such reductions not only directly lower the government's interest burden, but also dampen open market rates on government debt. By encouraging small investors to seek out savings avenues that offer better returns, a low interest rate regime directs such savings to mutual funds and shares, thus deepening stock markets. Hence with the change in the interest rate determination mechanism, the preference structure of households for financial assets will be altered. However, these effects may not be felt immediately but be staggered over a period of time.

Figure 1 presents evidence of the shifts in the pattern of holdings of financial assets. It graphs nominal values of financial assets in the household savings for the period 1970-71 to 2004-2005. Some assets have recorded explosive growth, particularly in the 1990s.

In Figures 2 to 5 we conduct a pair-wise comparison of the movements of the assets. There has been fluctuation of the currency holdings with respect to deposits with a slow upward trend until 1990-91 after which the trend dips. This reflects policy changes in relation to interest rates and changes in the technology of making financial transactions. Furthermore, the ratio of the insurance fund to provident funds has grown at a steady pace with acceleration after 1991-92. The contractual savings to deposit ratio also has a similar trend. The changing composition of savings components calls for a measure that could capture this substitution among assets. Aggregation over financial instruments requires that some conditions on the preferences of the public be fulfilled. Further, the weight assigned to each asset is not equal to one (as in the simple sum), but depends on the user cost, defined as the yield foregone to hold that instrument rather than holding the asset with the highest return which serves as a benchmark rate.

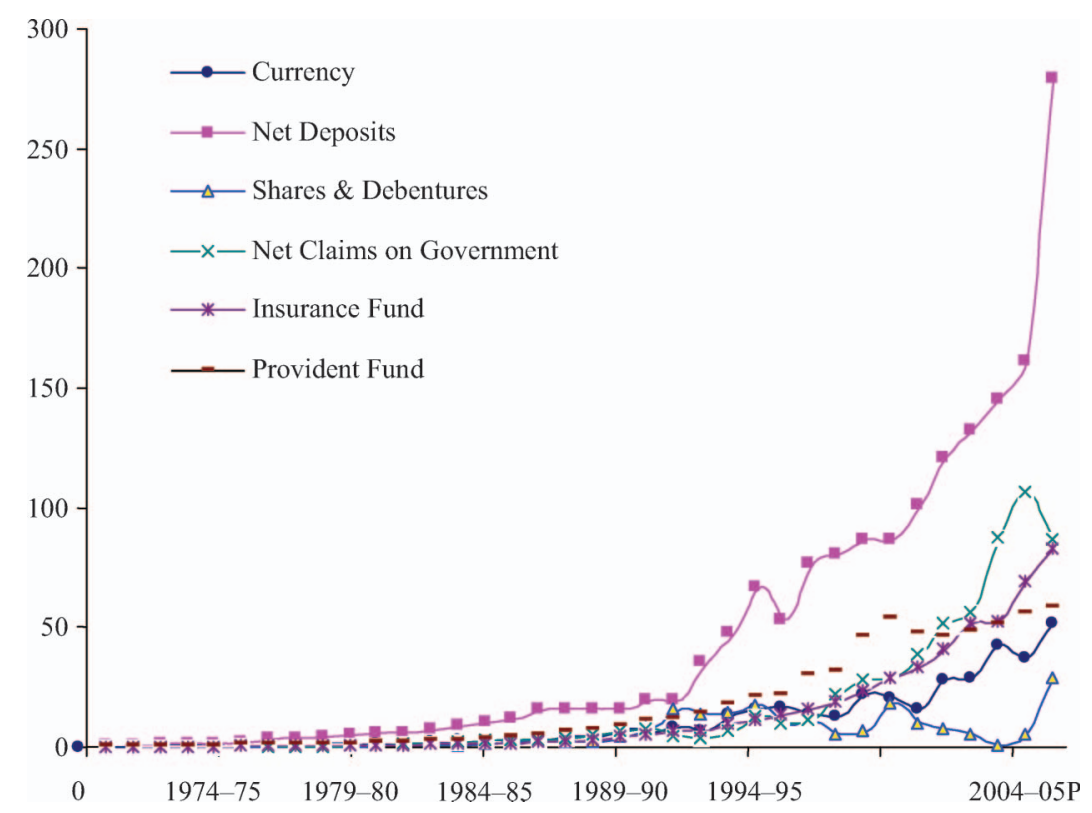

Figure 1. Net financial assets in household sector savings (Rs. 10 billion). Note: $\mathrm{P}=$ provisional. 


\section{Construction of Divisia indices}

Our motivation for considering the Divisia index is drawn from recent developments in the study of monetary aggregates and based on explicit microfoundations and on aggregation theory, and has the desirable property that the index's weights are variable. It measures the 'true' liquidity provided by monetary services. Diewert (1976) shows that the Divisia index is capable of measuring changes in a wide range of utility functions using only observed

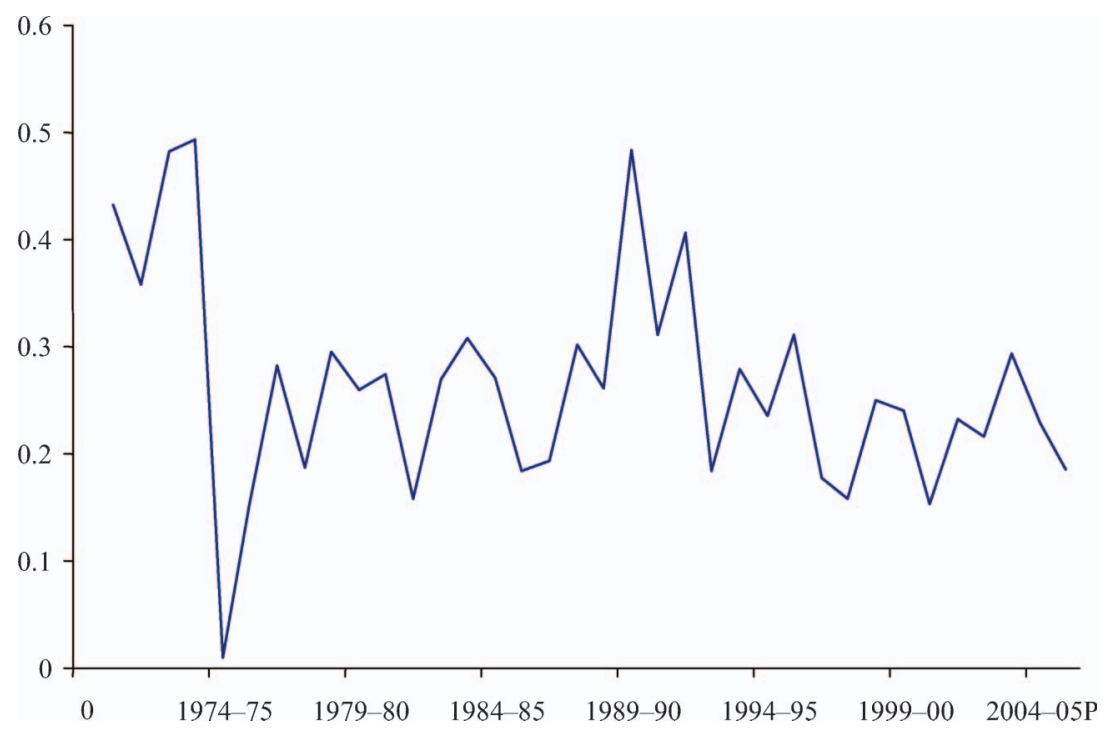

Figure 2. Currency to deposit ratio, 1970-2006. Note: $\mathrm{P}=$ provisional.

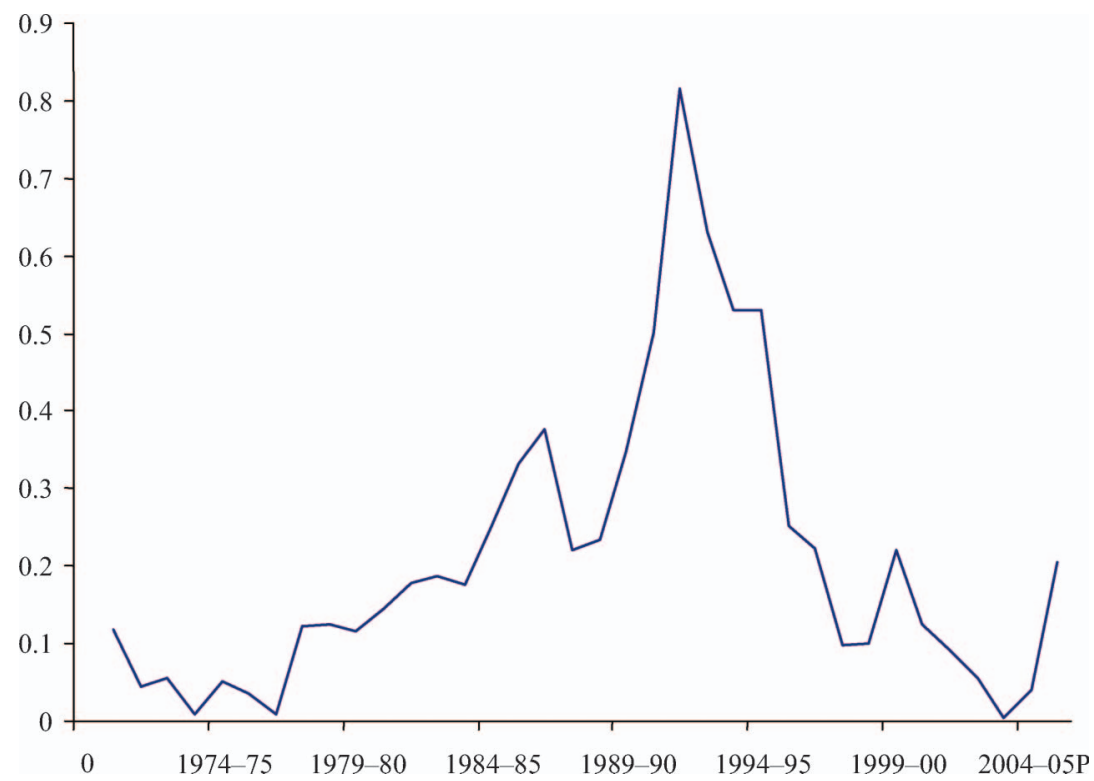

Figure 3. Shares and debentures to contractual savings ratio, 1970-2006. Note: $\mathrm{P}=$ provisional. 


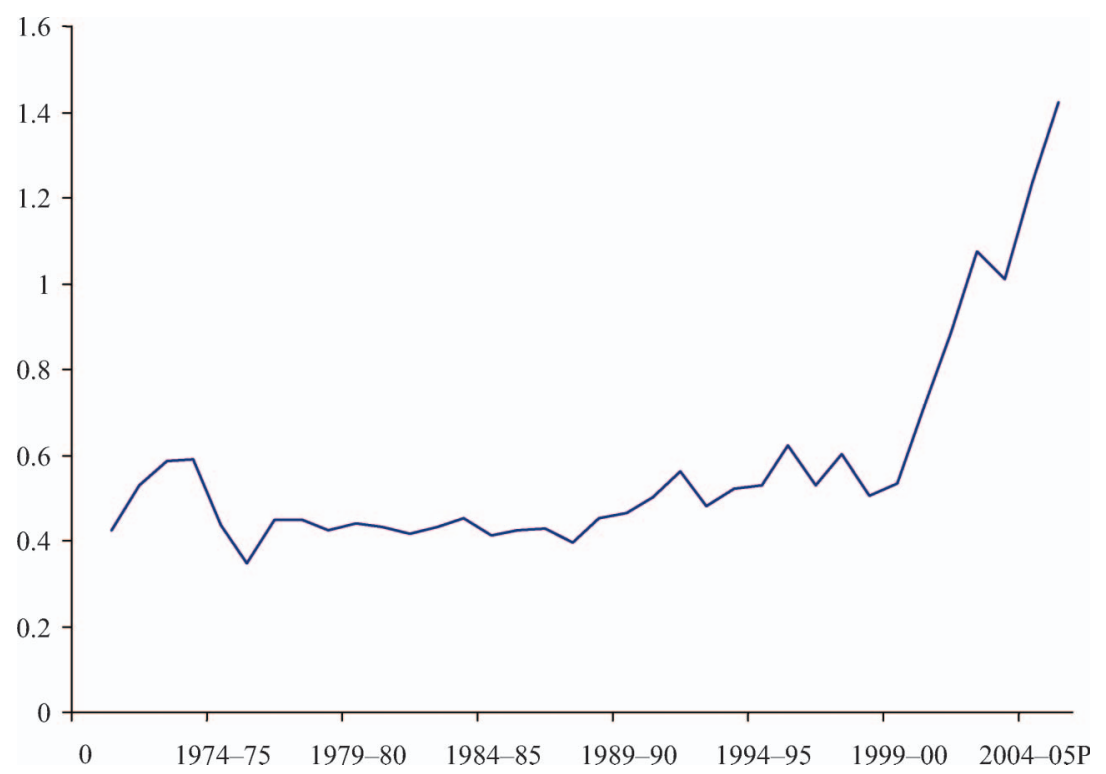

Figure 4. Insurance fund to provident fund ratio. Note: $\mathrm{P}=$ provisional.

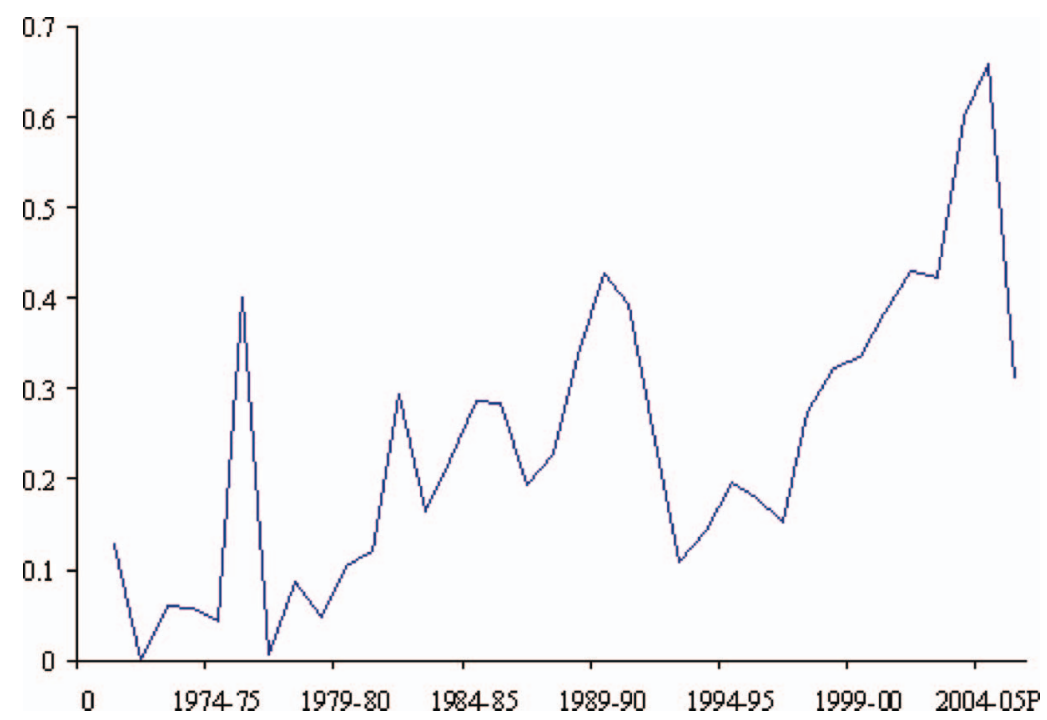

Figure 5. Net claims to deposit ratio, 1970-2006. Note: $\mathrm{P}=$ provisional.

prices and quantities. This result is directly applicable in measuring changes in economic aggregates. Although we cannot measure the 'true' quantity index, as we cannot observe the true utility function, we can approximate it using the Divisia quantity index. We use annual data for the period 1970-71 to 2004-2005. The data are drawn from RBI Bulletin, Reports on Currency and Finance: RBI and Handbook of Statistics on the Indian Economy: $R B I$.

When constructing the Divisia index, two questions are often pertinent: (i) which assets should be included in the Divisia aggregates or subaggregates and (ii) how the assets 
should be aggregated. Longjam (2003) and Jha and Longjam (2006) demonstrate that there exists weak separability between contractual and non-contractual assets. We, therefore, consider the following four subaggregates: (a) deposits, (b) shares and debentures, (c) net claims on government, and (d) the insurance fund. The constituents of each of the subaggregates are detailed in Table 1.

The real user costs of these component assets are constructed using the formula developed by the Federal Reserve Bank at St. Louis for own rates and benchmark rates. Using real user cost and nominal values of the financial assets, we construct financial subaggregates by using simple sum and Divisia subaggregates. We use Fisher's weak reversal test to ascertain corresponding prices of the Divisia subaggregate. Further, Laspeyer's index is used to estimate the corresponding prices for the simple sum subaggregates.

A Divisia index of financial assets measures the flow of financial services from the stock of such assets and, as such, is expressed in growth rates. The weights in the Divisia index are the shares of expenditures on the financial assets being aggregated. The expenditure share weights follow the idea of a step-wise budgeting problem in which monetary assets form one weakly separable group over which the individual allocates his/her expenditure on financial assets. The requirement here is that marginal rates of substitution between all pairs of assets within the group being aggregated be independent of the assets in other groups. An advantage of the Divisia index is its ability to internalize pure substitution effects.

A quantity index $Q\left(\pi_{t-1}, \pi_{t} ; m_{t-1}, m_{t}\right)$ of the financial assets between periods $t-1$ and $t$ is a function of the vector of the quantities of the assets $m_{t-1}>0$ and $m_{t}>0$ and vector of the respective user costs $\pi_{t-1}>0$ and $\pi_{t}>0$ and is exact if $Q\left(\pi_{t-1}, \pi_{t} ; m_{t-1}\right.$, $\left.m_{t}\right)=f\left(m_{t}\right) /\left(m_{t-1}\right)$ where $m_{t}$ maximizes the function $f(m)$ at $m>0$ subject to $\pi_{t}^{\prime} m \leq \pi_{t}^{\prime} m_{t}$. The Divisia index is one quantity index, which is always exact for any consistent function (Hulten 1973). A continuous time Divisia quantity index, $Q_{t}^{D}$, of the assets $x_{i t}$ is given by the differential equation:

$$
\frac{\mathrm{d} \log Q_{t}^{D}}{\mathrm{~d} t}=\sum_{i=1}^{n} s_{i t} \frac{\mathrm{d} \log x_{t}^{D}}{\mathrm{~d} t}
$$

for $i=1, \ldots, n$ and $s_{i t}=x_{i t}^{*} \pi_{i t} / \sum_{i=1}^{n} x_{i t}^{*} \pi_{i t}$ represents asset $i$ 's expenditure share.

Table 1. Financial components of four subaggregates.

\begin{tabular}{ll}
\hline Deposits & With banks \\
Shares and debentures & With non-banking companies ${ }^{\mathrm{a}}$ \\
& Private corporate business \\
& Units of Unit Trust of India (UTI) \\
Claims on government & Bonds of public sector undertakings \\
Insurance funds & Investment in government securities \\
& Investment in small savings \\
& Life insurance funds \\
& Other postal and state insurance funds \\
\hline
\end{tabular}

\footnotetext{
${ }^{a}$ Including deposits with cooperative banks and societies.

${ }^{\mathrm{b}}$ Including shares and debentures of cooperative banks and societies.

${ }^{\mathrm{c}}$ Including mutual funds other than UTI.
} 
The continuous-time Divisia quantity and user cost indexes satisfy Fisher's factor reversal test (Diewert 1976; Barnett 1980). In discrete time, the situation is quite different in that there is no statistical index number that is exact for any arbitrary aggregator function. Discrete time index number theory is based on two facts: (i) mathematical functions exist that can provide second-order approximations to unknown aggregator functions, and (ii) statistical index numbers exist that are exact for some of these functions. Diewert (1976) called a class of statistical index numbers superlative if they were exact for certain flexible forms. Two such important index numbers are (a) Fisher's ideal index and (b) the Tornqvist-Theil discrete time approximation to Divisia's continuous time quantity index. Fisher's ideal index is exact for a homogenous quadratic function while the latter is exact for the translog flexible form.

In this paper we construct the Tornqvist-Theil discrete time quantity index number, which is an approximation to the Divisia continuous time quantity index. The dual user cost index number $\Pi_{t}$ can be found by the recursive formula:

$$
\prod_{t}=\prod_{t-1}\left[\frac{\sum_{i=1}^{n} \pi_{i t} m_{i t}^{*}}{\sum_{i=1}^{n} \pi_{i t-1} m_{i t-1}^{*}}\right] \frac{M_{t-1}}{M_{t}}
$$

which is based on the factor reversal formula. As Anderson, Jones and Nesmith (1997) point out the financial service index and their dual user costs are chained superlative index numbers.

The simple sum index $S_{t}$ is given by the Laspeyer's index, $S_{t}=\sum_{i=1}^{n} p_{t}^{*} m_{i t}^{*}$, and measures the financial services flow only if the representative agent's indifference curves for the financial services are parallel lines, that is, they regard all assets as perfect substitutes. If the assets, in fact, have different user costs, then this agent will choose a corner solution and hold only one monetary asset in equilibrium. In the case of the static-expectation model introduced above, the simple sum index may be interpreted as a 'stock' variable; it is not however, a measure of the stock of monetary wealth. ${ }^{3}$

In the actual construction of Divisia indices, some practical problems arise. First, the results could be sensitive to the choice of the 'benchmark' interest rate; second under the restrictive policy in the financial system, the yield on the short-term rate may be greater than or equal to the benchmark rate in some years, causing the corresponding user cost to become negative; third the average of the market rates of some of the instruments are ad hoc. In our construction, we are cognisant of these possibilities. The simple sum construction, however, is based on very restrictive assumptions and an empirical comparison of the two approaches would be appropriate.

\section{Estimation}

In Table 2 we list all the assets along with proxies for the rates of return on them.

From the respective proxies for the rates of return on the assets, we estimate the user costs by using Barnett's formula (1978) after assigning a proxy rate for the benchmark asset. We take the highest rate of return among all assets as a proxy for the benchmark rate. We find the shares of each asset in the total expenditure. Since there are some negative values, we take the sum of the net value of the following assets: Bonds of Public Sector Undertaking, Investment in Government Securities and Investment in Small Savings, etc. This sum is called net claims on government. Similarly we have the Insurance Funds, which is the combination of the Life Insurance Funds and the Postal Insurance Funds. The proxies for the returns on these assets are 
Table 2. Financial assets and proxies for the rates of return.

\begin{tabular}{ll}
\hline Assets & Proxies \\
\hline Currency & Zero \\
Bank deposits & One-year rate on deposits \\
Non-banking deposits & One-year rate on private sector companies \\
Shares and debentures & Yield on ordinary shares \\
Units of UTI & Yield rate on units of UTI \\
Bonds of public sector units & Interest rates on public sector bonds \\
Investment in govt. securities & Yield rates on short-term govt. securities \\
Investment in small savings etc. & National saving certificates \\
Life insurance funds & Returns on the investment in LIC \\
Postal insurance funds & Three-year rate on postal savings deposits \\
Provident and pension funds & Rates on provident funds \\
\hline
\end{tabular}

taken as the weighted averages of the rates of return on the respective assets, the weights being the shares of the asset in the total asset. Thus we have eight assets: (i) Currency, (ii) Bank Deposits, (iii) Non-banking Deposits, (iv) Shares \& Debentures, (v) Net Claims on Government, (vi) Units of Unit Trust of India (UTI), (vii) Insurance Fund and (viii) Provident Funds. Using the GARP (Generalized Axiom of Revealed Preference) test for weak separability Jha and Longjam (2006) found preferences for the above assets to be weakly separable between the following three groups: (a) Bank Deposits and Non-Banking Deposits; (b) Shares \& Debentures and Units of UTI, and (c) Insurance Funds and Provident Funds.

The methodology for testing proceeds as follows. Having established the pattern of separability between the assets (see Jha and Longjam 2006), we construct two indices, namely, the Divisia quantity index and the simple sum quantity index numbers for the above three sub-utility functions. We use Fisher's weak reversal test to ascertain the corresponding prices of the Divisia subaggregate and Laspeyer's index to arrive at the corresponding prices for the simple sum subaggregates. There is evidence that since 199192 there has been a clear trend in the difference between the Divisia index and the simple sum index. Thus the importance of the distinction between the Divisia index and the simple sum increased sharply with financial liberalization - a fact corroborated by the significant values of $t$-statistics in Table 3, which gives the basic statistics of the difference between the Divisia and simple sum aggregates. The difference in shares and debentures has the largest mean and standard deviation. This lends further credibility to our attempt to improve upon the simple sum index.

We consider the above three aggregates together with currency and net claims on government. The user cost of the subaggregates in the case of the Divisia index is found by applying Fisher's reversal test, while in the case of the simple sum, we find the user costs using Laspeyer's index. Thus in both cases, we find the total expenses on the five financial subaggregates and hence the respective normalized prices.

We estimate the model using the financial subaggregates constructed and check for the stability and fitness of the model in terms of its ability to track the historical record.

\subsection{Simple sum and Divisia in expenditure-demand system analysis}

We would like to appraise the significance of the Divisia index vis-à-vis the simple sum in the performance of demand system analysis. For this, we estimate the 
same systems of demand equations as derived from the Fourier flexible form given as follows:

$$
f_{i}(x, \theta)=\frac{x_{i} b_{i}-\sum_{\alpha=1}^{A}\left\{u_{0 \alpha} x^{\prime} k_{\alpha}+\sum_{j=1}^{J}\left[u_{j \alpha} \sin \left(j k_{\alpha}^{\prime} x\right)+v_{j \alpha} \cos \left(j k_{\alpha}^{\prime} x\right)\right]\right\} k_{i \alpha} x_{i}}{x b-\sum_{\alpha=1}^{A}\left\{u_{0 \alpha} x^{\prime} k_{\alpha}+\sum_{j=1}^{J}\left[u_{j \alpha} \sin \left(j k_{\alpha}^{\prime} x\right)+v_{j \alpha} \cos \left(j k_{\alpha}^{\prime} x\right)\right]\right\} k_{\alpha}^{\prime} x}
$$

where

(1) $C=\sum_{\alpha=1}^{A} u_{0 \alpha} k_{\alpha} k_{\alpha}^{\prime}$,

(2) $\theta$ is a vector of the parameters $u_{0}, u_{j}$ and $v_{j}$ which are to be estimated,

(3) $k_{\alpha}, \alpha=1, \ldots, A$ is a sequence of multi-indices, ${ }^{4}$ and

(4) $x$ is a vector of the expenditure normalized user cost of the financial assets, with their locations shifted so that all $x$ comes in the positive rectangular orthant. The shifting has been done following Gallant's model (1981). ${ }^{5}$

The procedure of estimation is detailed in Longjam (2003). Here we focus mainly on the results of the estimation. The first task is to choose $A$ (the number of terms) and $J$ (the number of approximations). In our present case we choose, $A=12$ and $J=1$. The choice of $A(=12)$ helps to get a sufficient number of terms (according to significance of coefficients) while higher values of $J$ result in a significant loss of degrees of freedom. One equation in each system of equations has to be dropped so that the covariance matrix of the error terms is non-singular as the adding-up condition is imposed. The parameter estimates for this equation can be recovered from the other estimated parameters. In our case we drop the share equation of currency. We use an iterative non-linear Seemingly Unrelated Regression (SUR) with the restrictions of demand theory - linearity, homogeneity and symmetry - imposed on the system. However, we begin by estimating the system without any such restrictions and then impose the covariance matrix of the unrestricted model in the estimation of the restricted model. Table 4 reports the residual errors of the fitted model.

Table 3. Difference between the Divisia index and simple sum. ${ }^{\mathrm{a}}$

\begin{tabular}{lccr}
\hline Variables & Mean & Standard deviation & -Test $^{\mathrm{b}}$ \\
\hline Deposits & 1906.428 & 3773.718 & 3.03 \\
Shares and debentures & 18,181 & 27,264 & 4.00 \\
Insurance and provident funds & 1776.7 & 3863.3 & 2.76 \\
\hline
\end{tabular}

${ }^{\text {a }}$ The differences are in Rs. 10 million.

${ }^{\mathrm{b}}$ Test that the mean difference is different from zero.

Table 4. Nonlinear SUR summary of residual errors - Divisia index.

\begin{tabular}{lccccc}
\hline Equation & SSE & MSE & Root MSE & $R$-Square & Adj. $R$-square \\
\hline $\mathrm{Sh}_{2}$ & 0.0834 & 0.00303 & 0.0551 & 0.4319 & 0.2770 \\
$\mathrm{Sh}_{3}$ & 0.0585 & 0.00213 & 0.0461 & 0.6175 & 0.5131 \\
$\mathrm{Sh}_{4}$ & 0.0329 & 0.00483 & 0.0695 & 0.5747 & 0.3820 \\
$\mathrm{Sh}_{5}$ & 0.0213 & 0.00776 & 0.0279 & 0.8445 & 0.8034 \\
\hline
\end{tabular}


Under the maintained restrictions this estimation gives 34 parameters out of which only 10 are significant. However, this does not hamper our demand system approach. The main aim is to accurately measure the first- and second-order partial derivatives, which enables us to approximate the surface of the "true' functional form (Fisher and Fleissig 1994). Also we are able to check the testing of the hypothesis of the demand theories by using the subaggregate data of Divisia on the one hand, and the simple sum on the other.

The model is estimated using SAS. Test statistics are given as the objective value at the end of the table of the estimated results. For testing of the additivity case, the difference between the objective values in the case of the Divisia index is $(100.209-96.634)=3.575$ whereas in the simple sum case, it is $(99.436-40.441)=58.995$ with 1 degree of freedom. This shows that the linear homogeneity of the demand theory is decisively rejected in the data of the simple sum whereas it is accepted in the Divisia index case. However, in both cases we find that the demand systems are convergent only after a large number of iterations.

Tables 4 and 5 report on error residuals of the fitted model. The results are quite satisfactory with good $R^{2}$ values. In particular, the values of $R^{2}$ for the Divisia index have higher values in almost all cases than the simple and the sums of squares of the errors and their means are much smaller in the Divisia case than in the simple sum. So the Divisia index has a better fit in the demand system analysis than the simple sum.

\section{Information content of the financial aggregates}

We now report results from our analysis of the financial savings subaggregates for two indices: the Divisia and simple sum and construct an overall aggregate index of the subaggregates. We then examine the two indexes for their information content.

We construct the overall Divisia index for the financial assets in the household saving, consisting of the following assets: (i) currency, (ii) net claims on government and the three subaggregates we had constructed before, namely, (iii) the deposits, (iv) the shares and debentures, and (v) the insurance and provident fund. The user costs of the assets of currency and net claims on government are the same as those we described before, while the user costs of the three subaggregates are calculated by using the Fisher reversal test. The constructed Divisia index departs from its counterpart - the simple sum - over time and the departure is statistically significant. While the trends of the simple sum and Divisia are very similar, the departure of one from the other starts getting significantly stronger from the year 1990-91 with magnitudes of the differences amounting to billions of rupees. Figures 6 and 7 reveal the large difference of the Divisia index and simple sum in the presence of the financial innovations begun in 1991. Till 1987, the simple sum and Divisia indices of the financial moved together. But Figure 8 shows that from 1988 onwards, the difference between the two indices starts growing.

Table 5. Nonlinear SUR summary of residual errors - simple sum.

\begin{tabular}{lccccc}
\hline Equation & SSE & MSE & Root MSE & $R$-Square & Adj. $R$-square \\
\hline $\mathrm{Sh}_{2}$ & 0.0277 & 0.00363 & 0.0603 & 0.5196 & 0.3438 \\
$\mathrm{Sh}_{3}$ & 0.0838 & 0.00409 & 0.0639 & 0.4099 & 0.1939 \\
$\mathrm{Sh}_{4}$ & 0.0398 & 0.00194 & 0.0441 & 0.5685 & 0.4107 \\
$\mathrm{Sh}_{5}$ & 0.0287 & 0.00140 & 0.0374 & 0.6630 & 0.5397 \\
\hline
\end{tabular}




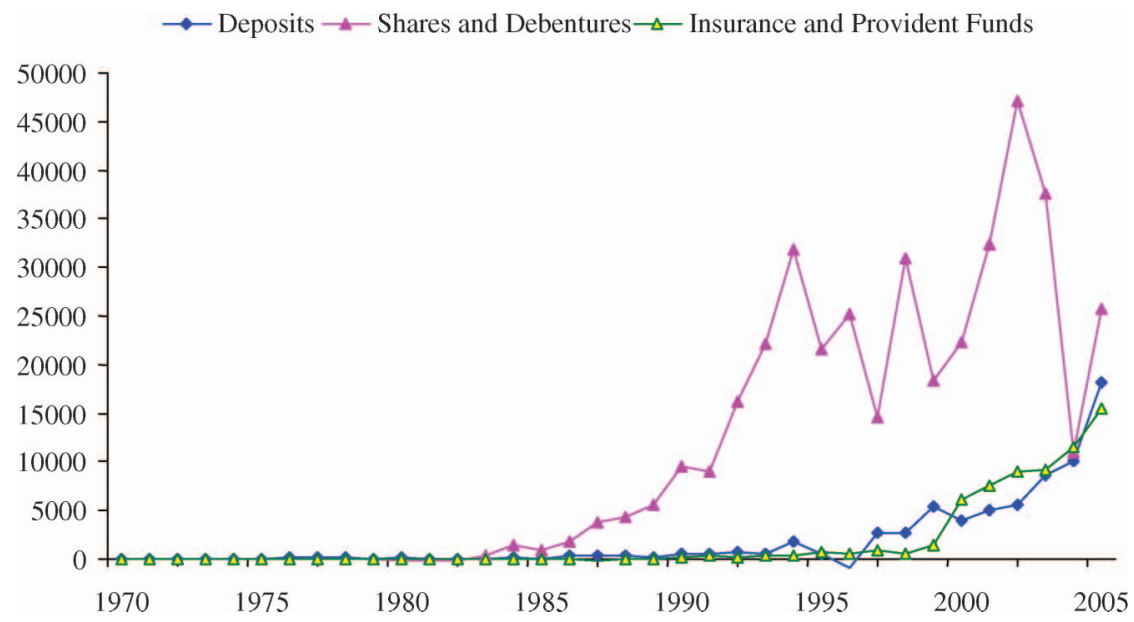

Figure 6. Component asset wise difference between simple sum and Divisia assets (Rs. 10 million).

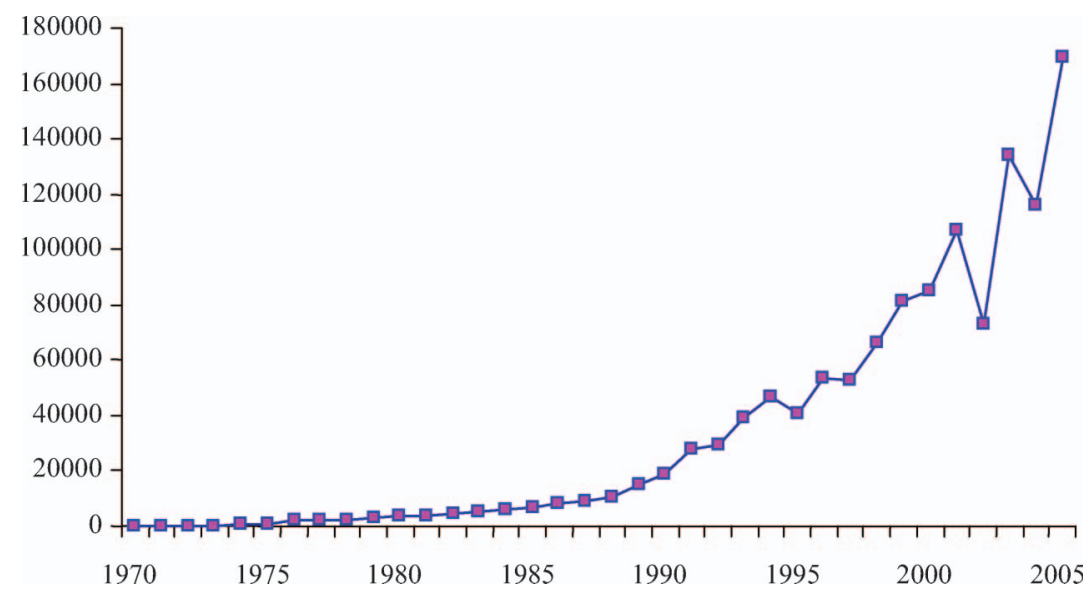

Figure 7. Difference between the simple sum and Divisia (Rs. 10 million).

Even by the end of 1998, the difference between the simple sum and Divisia index had risen to Rs. 362,671.7 million, which was roughly equivalent to the total number of available financial assets in the household sector in the year 1987. The standard deviation of the movement difference was Rs. 77,048.9 million with mean equal to Rs. $31,711.7$ million. The test statistics that the mean of the simple sum is different from that of the Divisia index is reported in Table 6.

\subsection{Methodology}

Following Shannon (1948), Theil (1969), Tinsley, Spindt and Friar (1980) and Gaab and Mullineux (1995), we measure the information content of the aggregates contemporaneously with respect to income. This is given as: $I(Y \mid F S)=-1 / 2 \ln \left(1-R^{2}\right)$ where $Y$ 


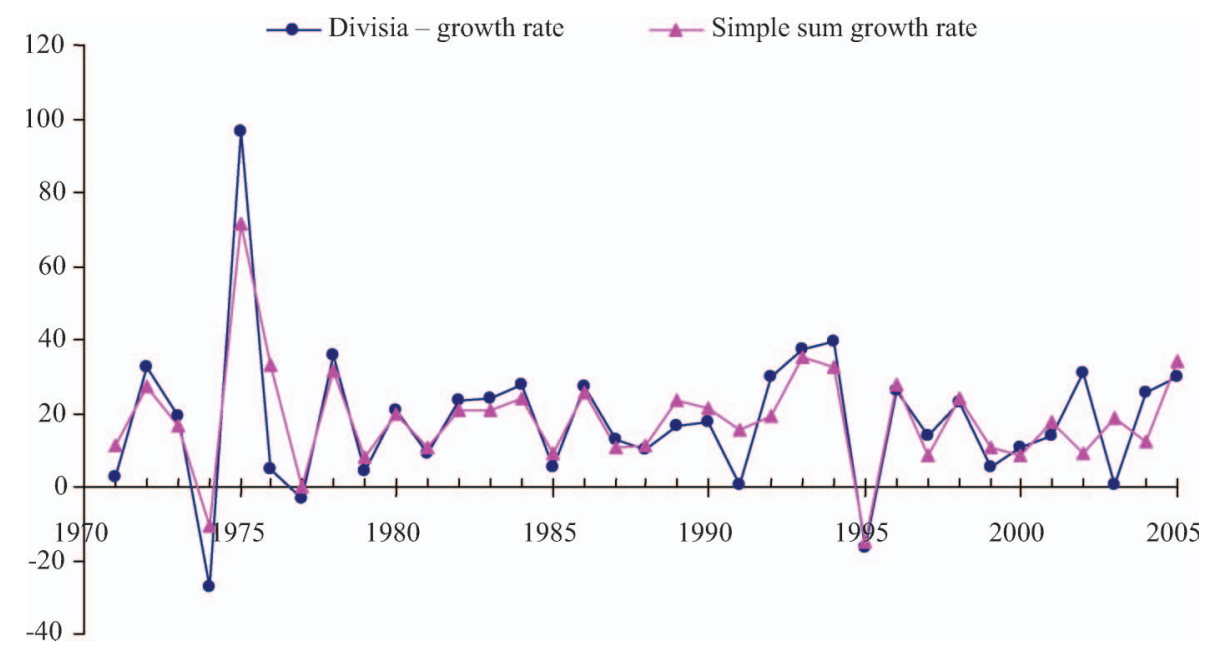

Figure 8. The growth rates of the simple sum and the Divisia (\%).

Table 6. Difference between the simple sum and Divisia index. ${ }^{\text {a }}$

\begin{tabular}{lccr}
\hline & Mean & Standard deviation & t-Stat $^{\mathrm{b}}$ \\
\hline Simple - Divisia & 19,192 & 43,817 & 4.66 \\
\hline
\end{tabular}

${ }^{\mathrm{a}}$ The differences are in Rs. 10 million.

${ }^{\mathrm{b}}$ Test that the mean is different from zero.

is the personal disposable income and $F S$ is the savings aggregate measure of the financial assets (simple sum or Divisia). $R^{2}$ is the coefficient of determination of the following linear regression equation:

$$
Y_{t}=\alpha+\beta F S_{t}+\varepsilon_{t}
$$

This procedure measures the value of using contemporaneous information based on the behaviour of $\varepsilon_{t}$. The above equation, however, makes the rather strict assumption that $\varepsilon_{t}$ has constant variance, zero serial correlation and zero non-contemporaneous correlation between $Y_{t}$ and $F S_{t}$. To avoid these strong assumptions, the above equation can be generalized to a dynamic framework by defining information content of $F S$ relative to $Y$ as follows $I(Y \mid F S)=-1 / 2 \ln \left(S S R_{2} / S S R_{1}\right)$ where $S S R_{1}$ and $S S R_{2}$ are sum of squared residuals from the following set of equations:

$$
\begin{aligned}
& Y_{t}=\alpha+\sum_{i=1}^{K} \beta_{i} Y_{t-1}+\varepsilon_{t} \\
& Y_{t}=\alpha+\sum_{i=1}^{K} \beta_{i} Y_{t-1}+\sum_{i=1}^{N} \theta_{i} F S_{t}+\varepsilon_{t} .
\end{aligned}
$$

If the second equation has a better fit than the first one, then we can say that FS provides information about $Y$ in addition to what $Y$ itself provides. This will involve testing the statistical significance of the values of $\theta$ in the second equation. This is similar to the Granger (1969) money-income causality tests. 
The usual $F$-statistics can be used to test for the joint statistical significance of the values of $\theta$. The test of the null hypothesis that $F S$ does not Granger cause $Y$ based on Equations (4) and (5) can be carried out with the following $F$-statistic:

$$
F=\frac{\left(S S R_{1}-S S R_{2}\right)(T-K-N-1)}{T-S S R_{2}}
$$

where $S S R_{1}$ and $S S R_{2}$ refer to the sum of squared residuals from ordinary least squares regressions on the above two equations, respectively. Here $T$ is the number of observations and $K$ and $N$ are the chosen lag length for $Y$ and $F S$, respectively. Under the null hypothesis, $F$ is distributed as $F$ with $(N, T-K-N-1)$. degrees of freedom. If the null hypothesis is rejected then $F S$ is not informative about $Y$.

\subsection{Results}

In estimating the above two equations, all variables are required to be stationary. We use the sequential scheme of multiple unit root tests, suggested by Dickey and Pantula (1987), that is, we first check for three unit roots, then two unit roots and finally a single unit root. These tests for a variable $x$ consist of regressing $\nabla^{3} x_{t}$ on $\nabla^{2} x_{t}-1$, then on $\nabla^{2} x_{t}$ and $\nabla x_{t-1}$. The procedure is continued until the coefficient on the most recently added variable is insignificantly different from zero.

After transforming all the series in their stationary form, we conduct the Granger causality test between savings and income. The lag lengths $K$ and $N$, are chosen using the Diebold and Nerlove (1990) 'rule-of-thumb' that consists in setting $K$ or $N=\operatorname{int}\left(T^{1 / 4}\right)$ where 'int' denotes the integer portion of the term in parentheses.

From the unit root test of the variables, we find that the saving aggregates under both the indices are $I(1)$ with the difference series having a significant trend. On the other hand, the personal disposable income is $I(2)$ with the difference series having a significant trend. Given our data-set, we find, following the 'rule-of-thumb', a round off integer of 2 for the maximum values of $K$ or $N$.

Therefore, we have the following linear regressions:

$$
\begin{aligned}
& \nabla^{2} Y_{t}=\alpha+\sum_{i=1}^{2} \beta_{i} \nabla^{2} Y_{t-1}+\varepsilon_{t} \\
& \nabla^{2} Y_{t}=\alpha+\sum_{i=1}^{2} \beta_{i} \nabla^{2} Y_{t-1}+\sum_{i=1}^{2} \theta_{i} F S_{t}+\varepsilon_{t} .
\end{aligned}
$$

Tables 7-9 give the results of the estimation of (7).

Table 7. OLS estimation of the first equation: Divisia index.

\begin{tabular}{lrrr}
\hline Regressor & Coefficient & Standard error & $t$-Ratio [prob] \\
\hline CONST & 9705.0000 & 4515.9000 & $2.1491[0.043]$ \\
DDPDY $(-1)$ & -0.7501 & 0.2190 & $-3.4248[0.002]$ \\
DDPDY $(-2)$ & 0.2424 & 0.3585 & $0.6761[0.506]$ \\
\hline
\end{tabular}

Note: Residual sum of squares $=7.10 \mathrm{E}+09$. 
Table 8. OLS estimation of the second equation: Divisia index.

\begin{tabular}{lrrr}
\hline Regressor & Coefficient & Standard error & $t$-Ratio [prob] \\
\hline CONST & 2708.7000 & 3035.0000 & $0.89251[0.383]$ \\
DDPDY $(-1)$ & -0.8315 & 0.2551 & $-3.2593[0.004]$ \\
DPDY $(-2)$ & 0.4804 & 0.2631 & $1.8258[0.083]$ \\
DDFS $(-1)$ & 1.1157 & 0.2167 & $5.1470[0.000]$ \\
DDFS $(-2)$ & -0.1049 & 0.3484 & $-0.3012[0.766]$ \\
\hline
\end{tabular}

Note: Residual sum of squares $=2.45 \mathrm{E}+09$.

Table 9. OLS estimation of the second equation: simple sum index.

\begin{tabular}{lrrr}
\hline Regressor & Coefficient & Standard error & $t$-Ratio [prob] \\
\hline CONST & 3141.2000 & 2941.0000 & $1.0680[0.298]$ \\
DDPDY $(-1)$ & -1.0144 & 0.2908 & $-3.4882[0.002]$ \\
DDPDY $(-2)$ & 0.3424 & 0.2984 & $1.1476[0.265]$ \\
DSFS $(-1)$ & 1.2434 & 0.2276 & $5.4618[0.000]$ \\
DSFS $(-2)$ & -0.1031 & 0.4092 & $-0.2521[0.804]$ \\
\hline
\end{tabular}

Note: Residual sum of squares $=2.36 \mathrm{E}+09$.

From these results, the calculated $F$-statistics as given by Equation (6) is (7.10E + $09-2.45 \mathrm{E}+09)(29-2-2-1) /(292.45 \mathrm{E}+09)$ for the Divisia, which is $F=1.570724842$ with $(2,24)$ degrees of freedom.

On the other hand, the calculated $F$-statistics for the simple sum is 1.601 with $(2,24)$ degrees of freedom. In both cases, we find the null of joint distribution is accepted. Thus in both cases financial savings are informative about income. However, it is difficult to judge from these figures of the $F$ distribution which index is more informative. The $I$-value in the case of Divisia (0.53) is almost indistinguishable from that for the simple sum (0.55).

Thus from a macrotheoretic sense one does not lose any significant information by using the Divisia as opposed to the simple sum whereas from the microtheoretic point of view the Divisia is clearly superior. Hence, on balance, the Divisia is the superior of the two indices.

\section{Conclusions}

With ongoing financial innovation and reform there are substantial effects on the relative user costs of the financial assets, leading to significant substitution among financial assets. In India, there has been fluctuation of the currency holdings with respect to the deposits since the 1970s, reflecting policy changes in respect of interest rates. Meanwhile, so far as contractual savings are concerned, the ratio of the insurance fund to the provident has grown at a steady pace with the pace picking up after 1991-92 with subsequent sharp peaks. Thus as the shifts occur in the user costs of the financial assets, the composition of the financial savings aggregate undergoes changes, which the standard method of simple sum cannot capture. This paper has constructed the more theoretically robust Divisia index and commensurate Divisia subaggregates of the financial assets component of household savings. Based on parametric and nonparametric tests of weakly separable hypothesis among the financial assets, we 
considered four subaggregates: (a) the deposits, (b) shares and debentures, (c) net claims on government, and (d) the insurance fund. The difference between the Divisia index and the simple sum has moved sharply after 1991-92. Among the constituent variables, the difference in shares and debentures has the largest mean and standard deviation, indicating that there has been a significant difference in the behaviour of the two indices. When we apply Fourier techniques in the demand system analysis to both the simple sum and Divisia subaggregates, we find the linear homogeneity of the demand theory being decisively rejected in the case of the simple sum but accepted in the Divisia index case. However, in both cases we find that the demand systems are convergent only after a large number of iterations. The figures of the error residuals of the fitted mode suggest to us that the Divisia index has a better fit in the demand system analysis than in the simple sum. Unit root tests reveal that the saving aggregates under both the indices are $I(1)$ with the difference series having a significant trend. On the other hand, personal disposable income is $I(2)$ with the difference series having a significant trend. An analysis of the information content of the two measures shows that they are about similar in this regard. Hence, while the Divisia is clearly superior to the simple sum from a microtheoretic sense it is no worse than it in a macroeconomic sense. On balance, then, the Divisia approach is preferable to the simple sum.

\section{Notes}

1. Forty per cent of the lending was to priority sectors, mainly the agricultural sector and smallscale industries and an additional 10\% went to export credit (Sen and Vaidya 1997).

2. Interest rates on loans up to Rs. 200,000 that account for $25 \%$ of the total advances are no longer controlled by RBI but constrained to be no higher than the prime lending rates (PLR) which are fixed by the boards of individual banks.

3. See Barnett (1990).

4. A multi-index is an $N$-vector of integer components so that its length, that is, the sum of the absolute components is less than some constant $K$. On the methodology for choosing $K$ and selecting the multi-indices, see Gallant (1981).

5. This shifting is a mere change of units. The shifting can be done as $x_{i}=\ln \pi_{i}+\ln a_{i}$ for $i=1$, $2, \ldots, n$, where $a_{i}$ values are chosen so that all values of $x_{i}$ are strictly positive in the given dataset. This is important in the present case because some of the net asset shares in the total financial savings come out to be negative.

\section{Notes on contributors}

Raghbendra Jha is Professor of Economics and Executive Director of the Australia South Asia Research Centre, within the Division of Economics at the Research School of Pacific and Asian Studies, The Australian National University, Canberra.

Ibotombi S. Longjam is Assistant Manager, ICSS Underwriting Risk Modelling, WWRIM, American Express, Gurgaon, India.

\section{References}

Ahluwalia, M.S. 1999. Reforming India's financial sector: An overview. In India: A financial sector for the twenty-first century, ed. J.A. Hanson and S. Kathuria. New Delhi: Oxford University Press.

Anderson, R., B. Jones, and J. Nesmith. 1997. Introduction to St Louis Monetary Services Index Project. Federal Reserve Bank of St. Louis Review 79, no. 1: 25-9.

Barnett, W. 1978. The user cost of money. Economics Letters 1, no. 2: 145-9.

1980. Economic monetary aggregates: An application of index number and aggregation theory. Journal of Econometrics 14, no. 1: 11-48. 
1982. The optimal level of monetary aggregation. Journal of Money, Credit and Banking 14, no. 4: 687-710.

. 1990. Developments in monetary aggregation theory. Journal of Policy Modelling 12, no. 2: 205-57.

Chetty, V. 1969. On measuring the nearness of near-moneys. American Economic Review 59, no. 3: $270-81$.

Dickey, D., and S. Pantula. 1987. Determining the order of differencing in autoregressive processes. Journal of Business and Economic Statistics 5, no. 4: 455-61.

Diebold, F., and M. Nerlove. 1990. Unit roots in economic time series: A selective survey. Advances in Econometrics 8: 3-70.

Diewert, W. 1976. Exact and superlative index numbers. Journal of Econometrics 4, no. 2: 115-45.

Drake, L., A. Mullineux, and A. Agung. 1997. One Divisia money for Europe? Applied Economics 29, no. 3: 775-86.

Fisher, D., and A. Fleissig. 1994. Money demand in a flexible dynamic Fourier expenditure system. Federal Reserve Bank of St. Louis Review 76, no. 2: 117-28.

Friedman, M., and A. Schwartz. 1970. Monetary statistics of the United States: Estimates, sources and methods. New York: Columbia University Press.

Gaab, W., and A. Mullineux. 1995. Financial innovation, monetary aggregates and monetary policy in the UK and Germany. Discussion Paper 95/17, University of Birmingham, Department of Economics.

Gallant, A. 1981. On the bias in the flexible functional forms and an essentially unbiased form: The Fourier flexible functional form. Journal of Econometrics 15, no. 2: 211-45.

Granger, C. 1969. Investigating causal relations by econometric models and cross-spectral methods. Econometrica 37, no. 3: 424-38.

Gupta, K. 1970. Household savings in financial assets: A case study of India. Indian Economic Journal 501-14.

Hirayama, K., and M. Kasuya. 1996. Financial deregulation and Divisia monetary aggregates in Japan. In Financial innovation, banking and monetary aggregation, ed. A. Mullineux. Cheltenham: Edward Elgar.

Hulten, C. 1973. Divisia index numbers. Econometrica 41, no. 6: 1017-25.

Jha, R., and I. Longjam. 2006. Structure of financial savings during Indian economic reforms. Empirical Economics 31: 861-9.

Longjam, I. 2003. The structure of financial savings in the Indian household sector. Unpublished PhD diss., Indira Gandhi Institute of Development Research, Mumbai, India.

Sen, P., and R. Vaidya. 1997. The process of financial liberalization in India. New Delhi: Oxford University Press.

Shannon, C. 1948. A mathematical theory of communication. Bell System Technical Journal 27: 379423 and $623-56$.

Theil, H. 1969. On the use of information theory concepts in the analysis of financial statements. In Consumer demand analysis and information theory: Advanced studies in theoretical and applied econometrics, eds. B. Raj and J. Koerts. Dordrecht: Kluwer Academic.

Tinsley, P., P. Spindt, and M. Friar. 1980. Indicator and filter attributes of monetary aggregates: A nit-picking case for disaggregation. Journal of Econometrics 14, no. 1: 61-91. 